\title{
Mild Protocol for the Synthesis of Functionalized Anilines from Potassium Aryltrifluoroborates
}

\author{
Everaldo F. Santos Filho*, Jokderlea C. Sousa, Paulo H. Menezes and \\ Roberta A. Oliveira \\ Departamento de Química Fundamental, CCEN, UFPE, 50670-901, Recife-PE, Brasil \\ everaldo.santosfo@ufpe.br
}

Keywords: potassium organotrifluoroborates, amination reaction, copper catalyst

\section{INTRODUCTION}

The aromatic C-N bond formation is of immense interest because aromatic amines and their derivatives are common in pharmaceuticals, agrochemicals, dyes, herbicides, and conducting polymers. ${ }^{1}$

Traditionally, the preparation of these amines has been performed by the reductive amination of aniline derivatives or aryl nitration/reduction sequences, which suffer from a lack of tolerance towards functional groups.

The organotrifluoroborates can be conveniently converted into different functional groups in a variety of ways. $^{2}$ In this context, the search of simple methods that can convert this compounds into its corresponding amine derivatives are of the great interest.

\section{RESULTS AND DISCUSSION}

The potassium organotrifluoroborates, $\mathrm{ArBF}_{3} \mathrm{~K}$, were prepared from the corresponding boronic acids according to the literature procedure (Scheme 1).

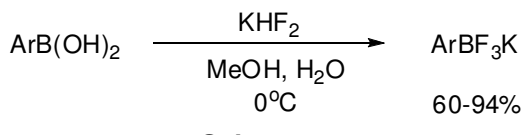

Scheme 1

These salts were then submitted to the amination reaction. Because ammonium hydroxide is an inexpensive, widely available, and industrially acceptable reagent, the reactions were catalyzed by $\mathrm{CuSO}_{4}$ using this material (Scheme 2).

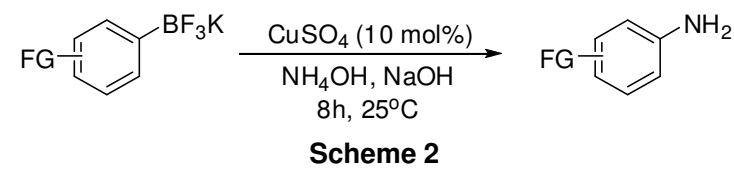

The results are depicted on Table 1 . The reaction provided good yields for the studied substrates containing different substituents. It is interesting to note that even when the nitro group was present, the corresponding amine was obtained in good yield.

Table 1: $\mathrm{CuSO}_{4}$ promoted the amination of potassium aryltrifluoroborates

Yield
$(\%)$

${ }^{a}$ Isolated yield

\section{CONCLUSION}

In summary, we have demonstrated the use of ammonium hydroxide and a catalytic amount $\mathrm{CuSO}_{4}$ under aerobic conditions to promote the synthesis of aromatic amines. The reaction is tolerant to several functional groups and the desired compounds were obtained in good yields.

\section{ACKNOWLEDGEMENTS}

The authors gratefully acknowledge CNPq, CAPES, FACEPE and INCT-INAMI for the financial support.

\section{REFERENCES}

${ }^{1}$ Kleist, W.;Pröckl S. S.; Dreesa, M.; Köhlera, K.; Djakovitch, L. J.Mol. Cat. A: 2009, 303, 15

${ }^{2}$ Oliveira, R. A. Synlett 2009, 505. 